\title{
Modeling hydrothermal, suspended solids transport and residence time in a deep reservoir
}

\author{
W. C. Liu • W. B. Chen
}

Received: 10 July 2011/Revised: 15 December 2011/Accepted: 23 March 2012/Published online: 19 December 2012

(c) CEERS, IAU 2012

\begin{abstract}
This article presents the modeling of hydrothermal characteristics and suspended solids in a long and large-volume reservoir with a highly fluctuating water level. A laterally averaged two-dimensional hydrothermal and water quality model was configured for the Shihmen Reservoir in northern Taiwan. The model was validated with measured data of water surface elevation, water temperature, and concentration of suspended solids in 2006. The results show that the numerical model was able to reproduce the measured data. The validated model was then used to investigate the effects of water withdrawal schemes at different depths and to estimate the residence time in the reservoir. When water is withdrawn from a great depth, the relatively warm water from the upper layers can replace that in the deep layers, thereby facilitating heat transfer from the surface to the deeper layer. Bottom-water withdrawal results in a lower concentration of suspended solids compared with withdrawal from depths of 20 and $40 \mathrm{~m}$. The simulated results show that the residence time is approximately 154 days in the Shihmen Reservoir.
\end{abstract}

Keywords Hydrodynamic - Numerical model . Validation · Water level · Water quality

W. C. Liu ( $\square)$

Department of Civil and Disaster Prevention Engineering, National United University, Miao-Li 36003, Taiwan

e-mail:wcliu@nuu.edu.tw

W. B. Chen

Supercomputing Research Center, National Cheng Kung University, 70101 Tainan, Taiwan

\section{Introduction}

Reservoirs are usually built to store water for water supply, irrigation, flood control, and power generation. Inflow and withdrawal may lead to a decrease in a reservoir's retention time. A deep and large reservoir behaves like a river depending on the residence time. Thermal stratification is a common characteristic of deep reservoirs located in temperate and subtropical regions. The stratification of a reservoir is the result of various physical processes that distribute heat from the surface to its deeper layers. These processes depend not only on meteorological conditions, but also on the biochemical characteristics of the water body.

Density currents can transport suspended solids from the watershed to downstream reservoir regions (Wetzel 2001) and may cause sedimentation (De Cesare et al. 2001). A high concentration of total suspended solids has adverse effects on freshwater ecosystems, such as impeded phytoplankton growth (Thornton et al. 1990), spoiled water quality, and interference from grazing by cladoceran zooplankton (Kirk 1991; Soeken-Gittinger et al. 2009).

Appropriate reservoir operation can prevent sedimentation or water quality deterioration. Such management requires understanding of the hydrodynamic characteristics and transport of suspended solids in reservoirs, and to establish comprehensive plans that minimize the adverse effects of suspended solids with nutrients or pollutants in reservoir ecosystems.

Taiwan is located in monsoon climate regions, and the environmental impacts of reservoir turbidity flows induced by flood runoffs and soil erosion processes in watersheds are critically significant and a major consideration for reservoir operations. Particularly important is the flow path and residence time of contaminated turbidity flows induced 
by heavy rainfall and runoff events during the summer season. In the present study, a two-dimensional hydrothermal/transport model is adopted to simulate the hydrothermal and suspended solids transport in the stratified Shihmen Reservoir of northern Taiwan. The model simulation was validated against profiles of water temperature and time variations of suspended solids in 2006. The validated model was then applied to assess the effectiveness of different selective withdrawal depths on the control of reservoir outflow suspended solids and the impacts on the stratification patterns. The reservoir's residence time was also calculated and is discussed with the validated model.

\section{Materials and methods}

\section{Characteristics of study site}

The Shihmen Reservoir, located upstream of the Tahan Stream in northern Taiwan (Fig. 1a), satisfies the multiple purposes of irrigation, hydropower generation, industrial and domestic water uses, flood control, and recreation. The Tahan Stream has a length of $135 \mathrm{~km}$ with an average channel slope of 1/37, and its watershed covers an area of $1,163 \mathrm{~km}^{2}$. The watershed has received an average of $2,410 \mathrm{~mm}$ of rainfall over the last forty years; however, the rainfall is uneven with more than $70 \%$ occurring between May and October (typhoon season). Since its commissioning in 1964, the reservoir has contributed much to the agricultural and industrial development in northern Taiwan, improved standards of living, increasing employment opportunities, and preventing calamities resulting from floods and droughts. The watershed of the Shihmen Reservoir is $16.5 \mathrm{~km}$ long and covers an area of $763.4 \mathrm{~km}^{2}$, with an effective storage capacity of $2.35 \times 10^{8} \mathrm{~m}^{3}$. The crest elevation of the dam is at $252.1 \mathrm{~m}$ and the top of the flood control pool is at an elevation of $250 \mathrm{~m}$. The normal maximum water level of the conservation pool is $245 \mathrm{~m}$ and the dead water level is $195 \mathrm{~m}$. There are six tainter floodgates of an ogee-type concrete spillway, each $14 \mathrm{~m} \times 10.61 \mathrm{~m}$ with a minimum discharge of $600 \mathrm{~m}^{3} / \mathrm{s}$ and a maximum discharge up to $11,400 \mathrm{~m}^{3} / \mathrm{s}$. There are two tunnel spillways with a minimum discharge of $200 \mathrm{~m}^{3} / \mathrm{s}$ and a maximum discharge $2,400 \mathrm{~m}^{3} / \mathrm{s}$.

The water level is frequently lower during the dry season to store water inflows during the typhoon periods in the Shihmen Reservoir. Therefore, the water level greatly fluctuates between the dry and typhoon seasons. Impoundments are often turbid because of inflows laden with high concentrations of suspended solids derived from the upstream watershed during the typhoon period.
Reservoir inflows have greater density than waters because of the lower temperature and higher suspended solids concentration during the wet season.

\section{Model description}

In this study, the CE-QUAL-W2 (call W2) model is adopted and applied to a deep reservoir to simulate the hydrothermal and suspended solids concentration. W2, developed by the Army Corps of Engineers' Waterways Experiment Station (Cole and Buchak 1995), is a vertical two-dimensional hydrodynamic and water quality model. Because the model assumes lateral homogeneity, it is particularly suitable for water systems with little lateral variations of hydrodynamic and water quality constituents in long and narrow water bodies. The topography of the Shihmen Reservoir is especially suitable for W2 applications. The W2 model uses a numerical scheme for a direct coupling between hydrodynamic and water quality simulations. The W2 model has been widely employed in many stratified lakes and reservoirs (Bartholow et al. 2001; Kuo et al. 2003; Sullivan et al. 2003; Kim and Kim 2006; Gelda and Effler 2007; Zhang et al. 2008; Afshar and Saadatpour 2009; Chung and Gu 2009; Etemad-Shahidi et al. 2009).

The W2 model is based on a finite difference approximation to the laterally averaged equations of fluid motion including: (1) the free surface wave equation; (2) continuity; (3) horizontal momentum; (4) hydrostatic pressure; (5) equation of state; and (6) constituent transport. The model quantifies the free surface elevation, pressure, density, horizontal and vertical velocities, and constituent concentrations. In W2 model applications, the hydrodynamic runs provide real-time simulations of water level, velocities, and temperature to constituent transport equations. The water quality module can simulate 21 constituents. Users have the option to choose a subset of interrelated constituents in the simulation. A detailed description of the W2 model can be found in Cole and Wells (2000). Coefficients used in the model have been presented in Table 1.

The W2 model has several parameters that should be carefully tuned through a validation process. These parameters include longitudinal eddy viscosity and diffusivity, the Chezy coefficient, and the wind-sheltering coefficient, which affects the water temperature in the reservoir. The fraction of incident solar radiation absorbed at the water surface and the coefficient for the bottom heat exchange affect the heat budget. For the simulation of suspended solids transport, the settling velocity significantly influences the distribution of the concentration in the reservoir. 
Fig. 1 a Location map of the Shihmen Reservoir and $\mathbf{b}$ finite difference grid representation for the modeling (a)
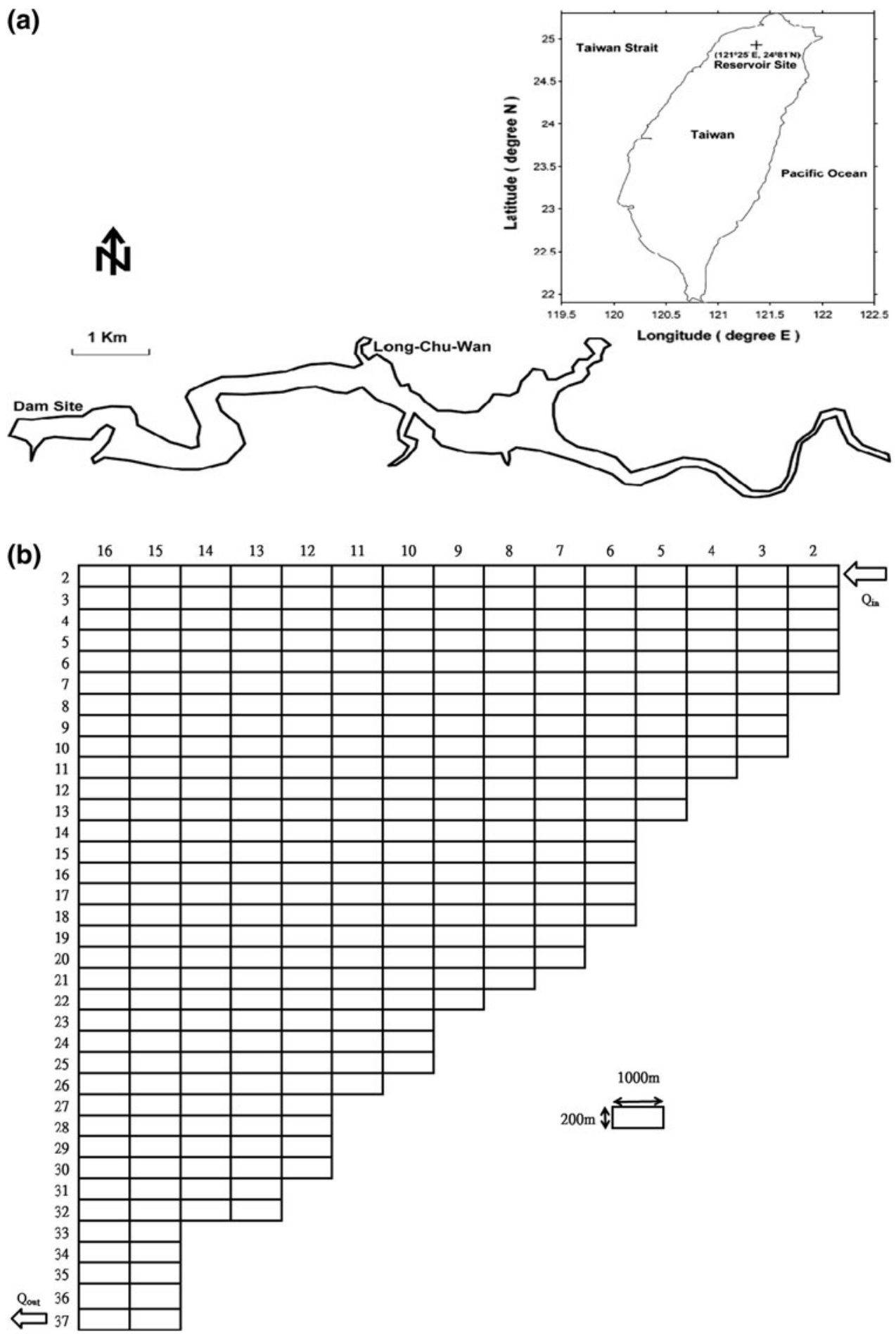

\section{Results and discussion}

Model validation

The fundamental input data for W2 included reservoir topography and bathymetry, stream temperature, flow, quality records, and meteorological logs. The reservoir topography is used to define the finite difference representation of a waterbody. According to this representation, the Shihmen Reservoir is described as a single branch waterbody with 15 longitudinal segments and 36 vertical layers (Fig. 1b). The segment length and layer thickness are selected to be 1,000 and $2 \mathrm{~m}$, respectively. The entire water column is, therefore, configured with a total of 326 cells. The main inflow data are supplied from one gauge station. Stream inflows from small, ungauged tributaries are appropriated 
Table 1 Coefficients used in the model

\begin{tabular}{lll}
\hline Coefficient & Unit & Value \\
\hline Horizontal eddy viscosity & $\mathrm{m}^{2} / \mathrm{s}$ & 1.0 \\
Horizontal eddy diffusivity & $\mathrm{m}^{2} / \mathrm{s}$ & 1.0 \\
Chezy coefficient & $\mathrm{m}^{0.5} / \mathrm{s}$ & 70.0 \\
Wind-sheltering coefficient & - & 0.85 \\
Coefficient of bottom exchange & $\mathrm{W} / \mathrm{m}^{2} / \mathrm{s}$ & $7.0 \times 10^{8}$ \\
Settling velocity & $\mathrm{m} / \mathrm{day}$ & 1.0 \\
\hline
\end{tabular}

according to their watershed areas. The meteorological data were obtained from the Taiwan Northern Region Water Resources Bureau. Daily average meteorological data were used to calculate solar radiation, equilibrium temperature, and the surface heat exchange coefficient. Monthly water temperature and SS data in the reservoir were used for computing the model results.

The hydrothermal model was validated with 2006 data. The inflow and outflow discharges are presented in Fig. 2a. Several peaks in inflow and outflow discharges occurred due to the typhoon events. Figure $2 b$ presents a close match between the simulated and measured water surface elevation in the Shihmen Reservoir. The timeseries data indicate that the water surface elevation decreases gradually and reaches the lowest in spring and the early summer months, then gradually rose and reached a peak in the late summer and autumn typhoon periods. In the winter months, the water surface elevation remains relatively constant. The maximum fluctuations in the water surface elevation reached approximately $17 \mathrm{~m}$ in 2006.

A good model performance is indicated by the calculated absolute mean error (AME) and root-mean-square error (RMSE) statistical values. The AME and RMSE between the computed and observed water surface elevation are 0.6 and $0.84 \mathrm{~m}$, respectively.

Water temperature data were used to evaluate the hydrothermal results from one-year runs. Figure 3 presents the vertical profiles of simulated and measured water temperatures at the dam site. Note that the model simulation results closely mimic the measured water temperature and exhibit a pronounced vertical thermal gradient in the summer, then significantly overturning by the end of fall. The AME and RMSE values at the dam site are 0.47 and $0.62{ }^{\circ} \mathrm{C}$, respectively.
Fig. 2 a Inflow and outflow discharges for 2006 , b comparison of simulated and measured water surface elevation in 2006
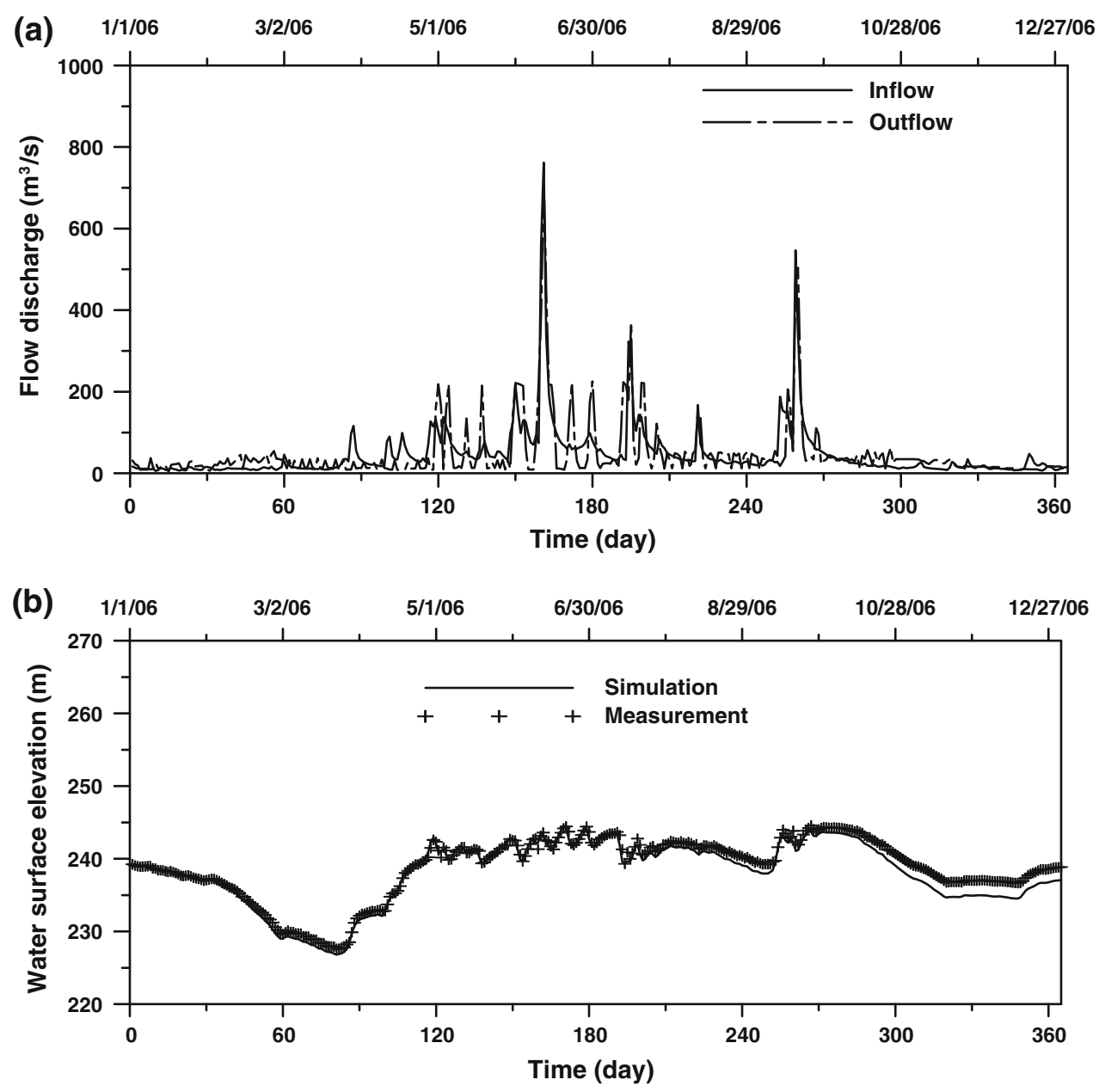

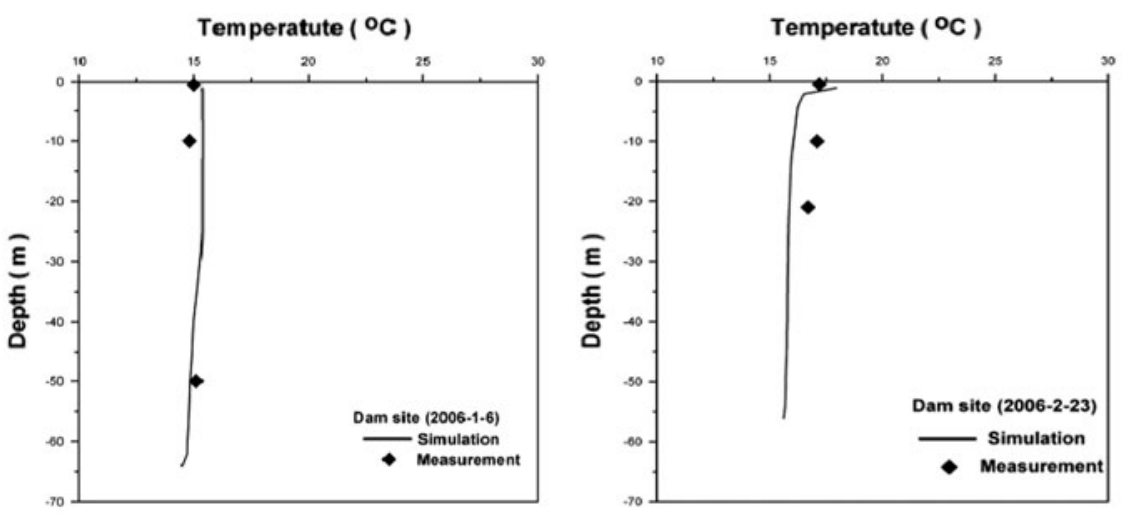

Temperatute $\left({ }^{\circ} \mathrm{C}\right)$
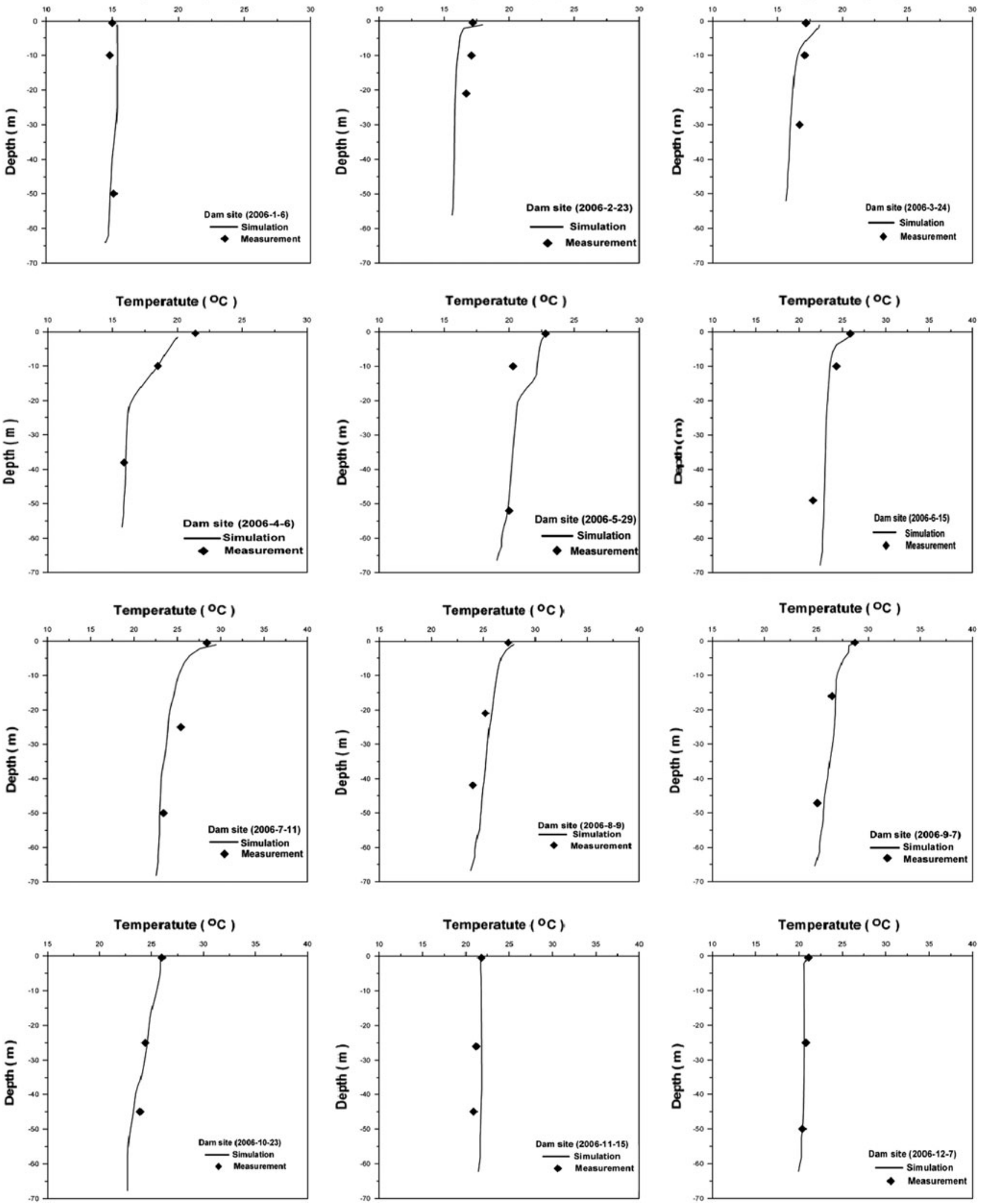

Fig. 3 Comparison of vertical water temperature profiles between model simulation and observation at the dam site in 2006 
For the SS concentration modeling, the settling velocity is a significant coefficient that needs to be calibrated in the model. The settling velocities of SS are a function of particle type, grain size, density, viscosity, and turbulence. The model uses a net settling velocity to account for these factors, and it is determined by the users who choose an appropriate value based upon the measured SS data. Figure 4 illustrates a comparison of a simulated and measured SS concentration at the surface, middle, and bottom layers. Obviously, the SS concentration at the bottom layer is higher than that at surface and middle layers, revealing that the simulated results match the observed SS concentration fairly well. The AME and RMSE values are 0.60 and $1.12 \mathrm{mg} / \mathrm{L}$, respectively. A settling velocity of $1 \mathrm{~m} /$ day was adopted for the model validation results.

Effects of water withdrawal schemes at different depths

The effects of water withdrawal have been found to be important in determining the thermal stratification in
Fig. 4 Comparison of timeseries suspended solids concentrations between model prediction and observation at the dam site in 2006
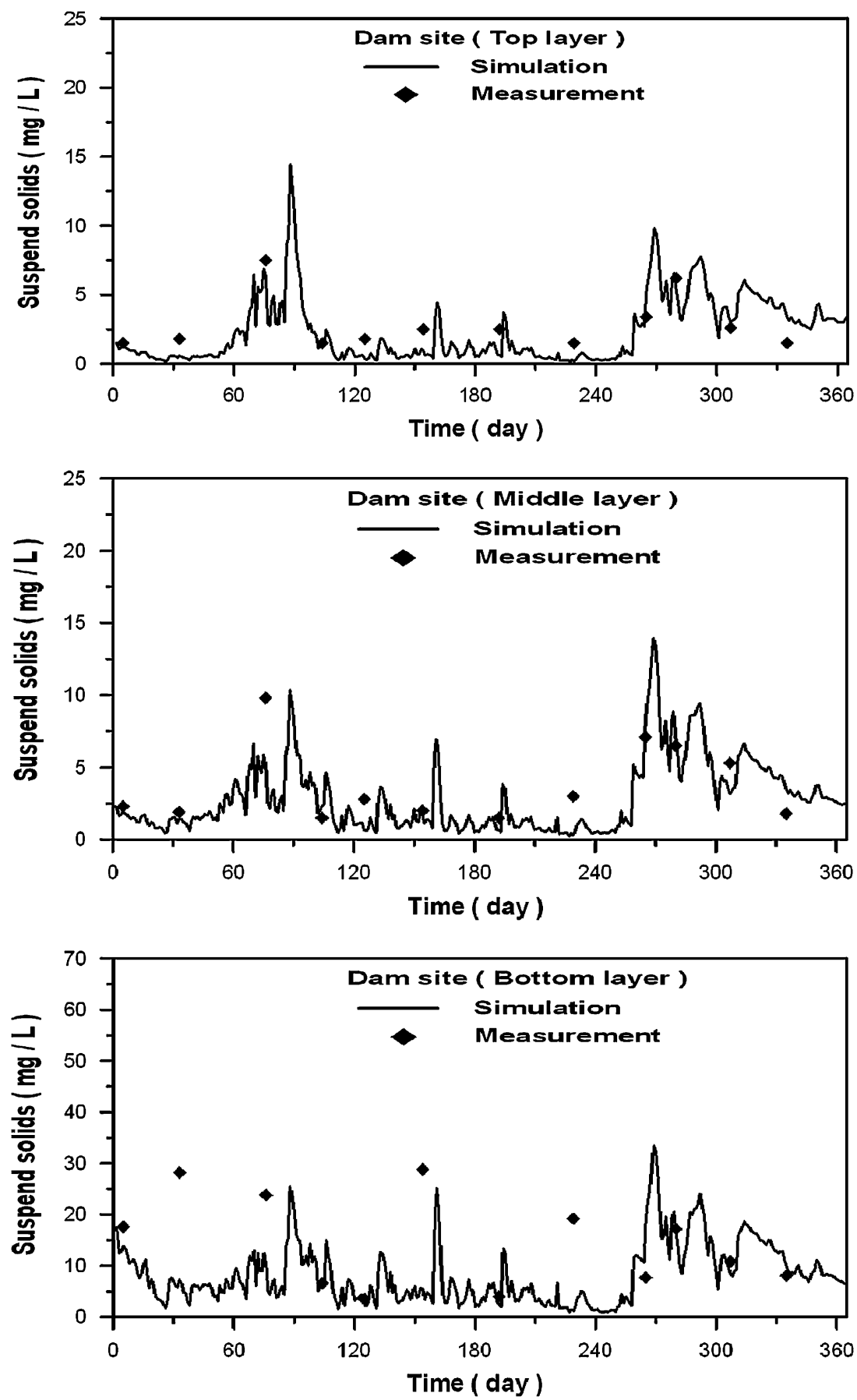
reservoirs (Ford 1990). In the Shihmen Reservoir, water is usually released (withdrawal) from the bottom part of the dam site. The manipulation of withdrawal depth to generate selective withdrawal layers can be an effective strategy to change the stratification and turbid inflow propagation in the reservoir. To investigate the role of water withdrawal schemes on stratification and SS propagation, the model simulations of three different withdrawal schemes were of the following: (1) the original withdrawal depth at the bottom part of the dam site; (2) water withdrawal at a depth of $40 \mathrm{~m}$; and (3) water withdrawal at a depth of $20 \mathrm{~m}$. All other reservoir conditions were kept identical.

Figure 5a presents a comparison of the seasonal variations in the predicted water temperature below the water surface at a $20 \mathrm{~m}$ depth at the Dam site corresponding to different water withdrawal schemes. In the summer season, the maximum water temperature below $20 \mathrm{~m}$ with bottomwater withdrawal is $2.5^{\circ} \mathrm{C}$ higher than that with withdrawal from $20 \mathrm{~m}$. The simulated results suggest that water withdrawals from deeper depths would facilitate heat transfer in the water column from the surface down to the water withdrawal depth and, therefore, could weaken the thermal stratification in the water layers above the withdrawal depth.
The snapshot plots of the simulated SS concentration are presented in Fig. 6. The plunging and separation depths and the vertical extent of the plume are greatly affected by the changing of the withdrawal depths at the dam site. Bottom-water withdrawal results in a lower SS concentration compared with withdrawal from 20 and $40 \mathrm{~m}$. A comparison of seasonal variations in predicted SS concentrations below $20 \mathrm{~m}$ at the dam site corresponding to different water withdrawal schemes is shown in Fig. 5b. The figure reveals that bottom-water withdrawal significantly decreases the SS concentration in the summer season, and considerably alters the peak time of the SS concentration.

\section{Residence time}

A first-order description of transport is expressed as residence time, which is a measure of water-mass retention within defined boundaries. Scientists often estimate retention time to compare the time scales of input or biogeochemical processes (Ambrosetti et al. 2003).

The residence time is estimated to investigate the possibility of physical transport mechanisms. The experiment
Fig. 5 Comparison of predictions of a water temperature and $\mathbf{b}$ suspended solids $20 \mathrm{~m}$ below the water surface at the dam site corresponding to different water withdrawal depths
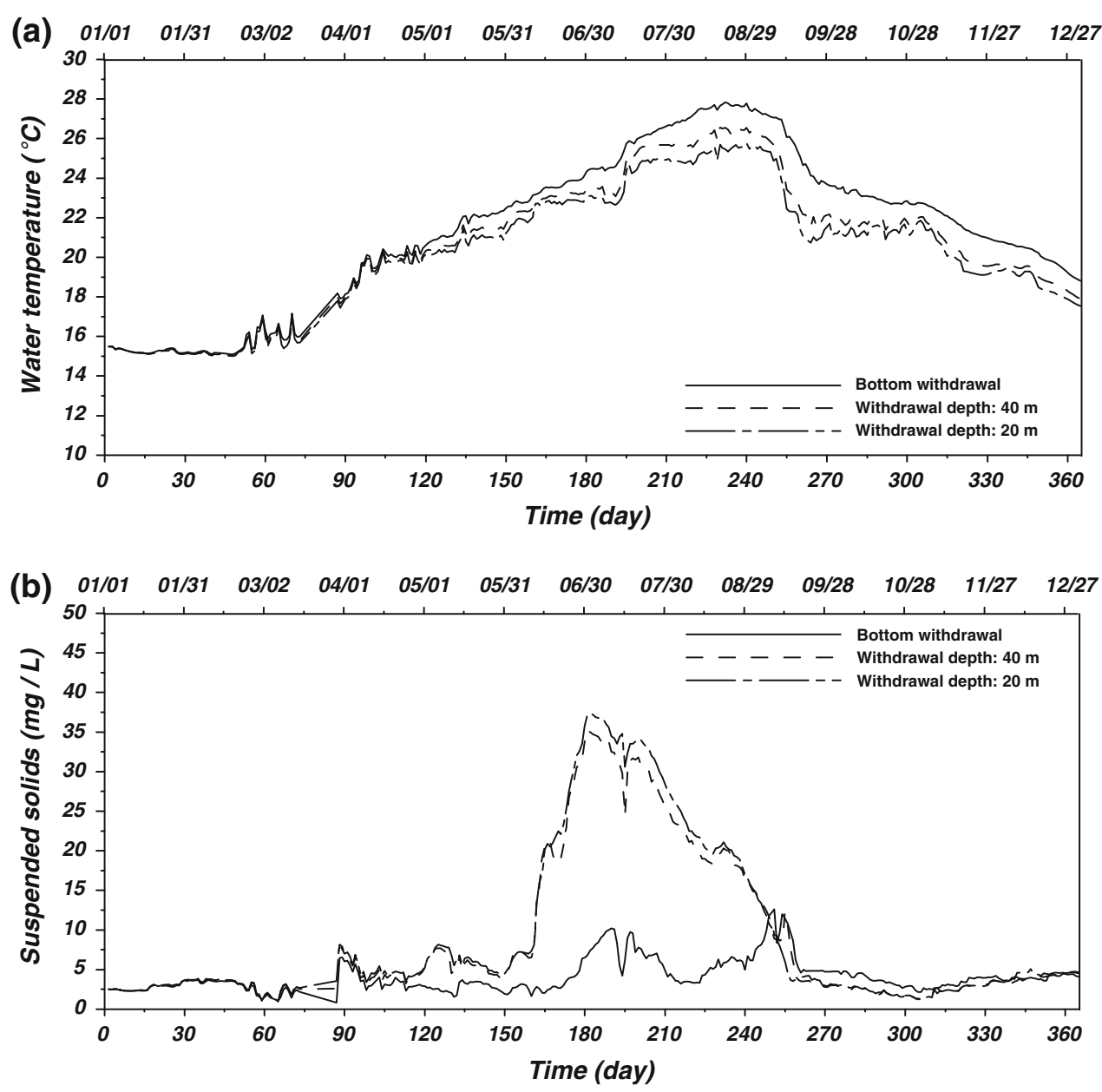

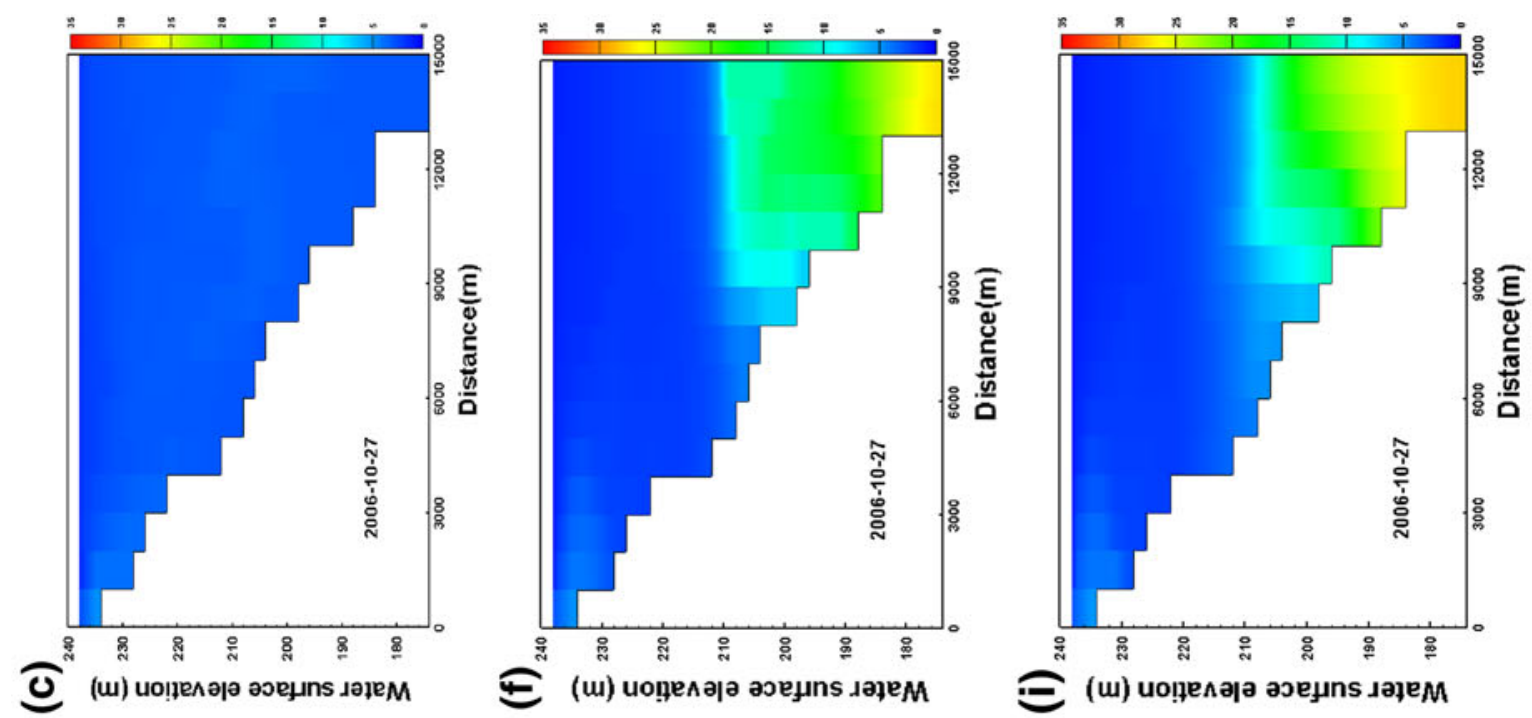

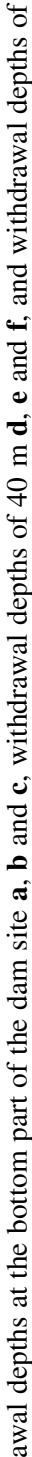

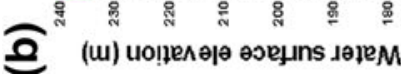
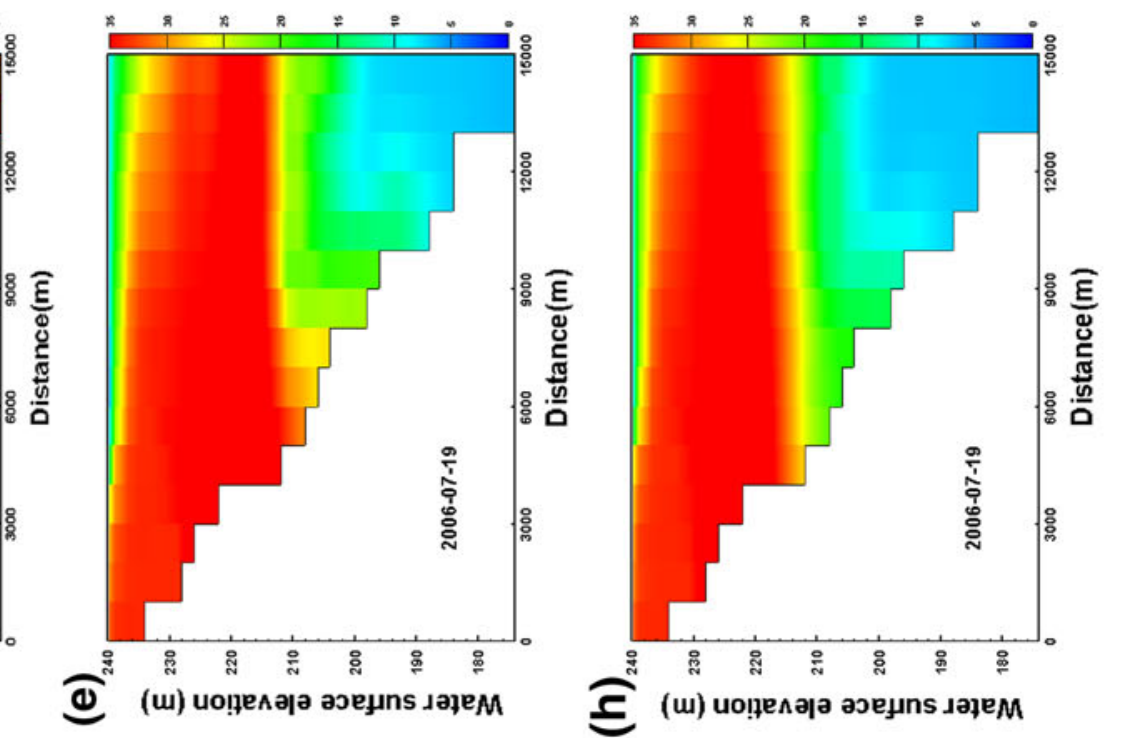

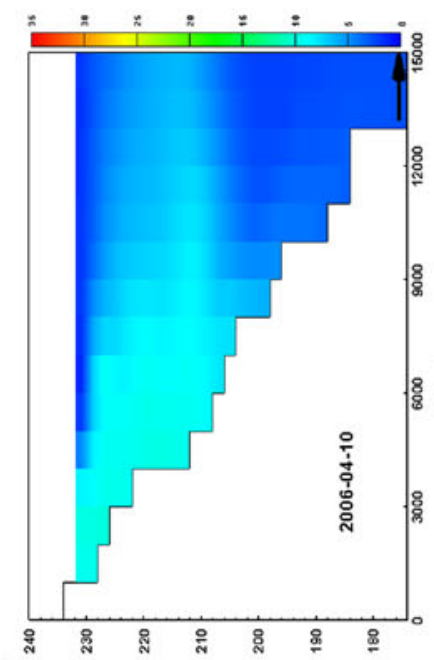

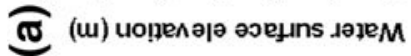

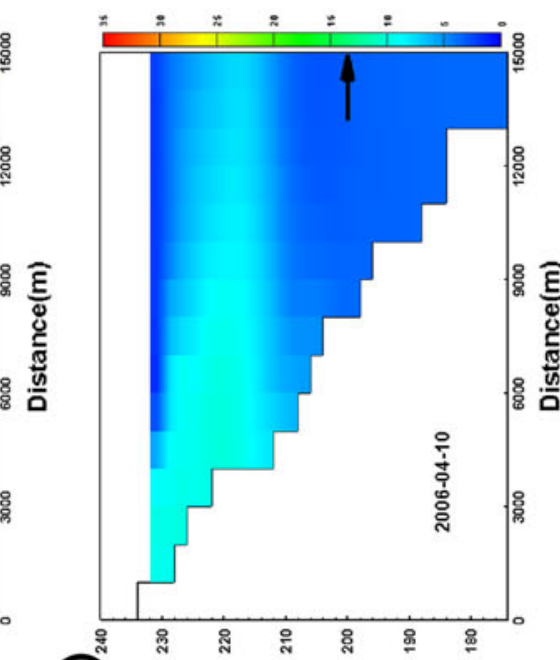

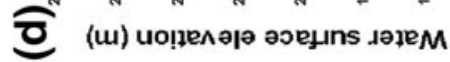

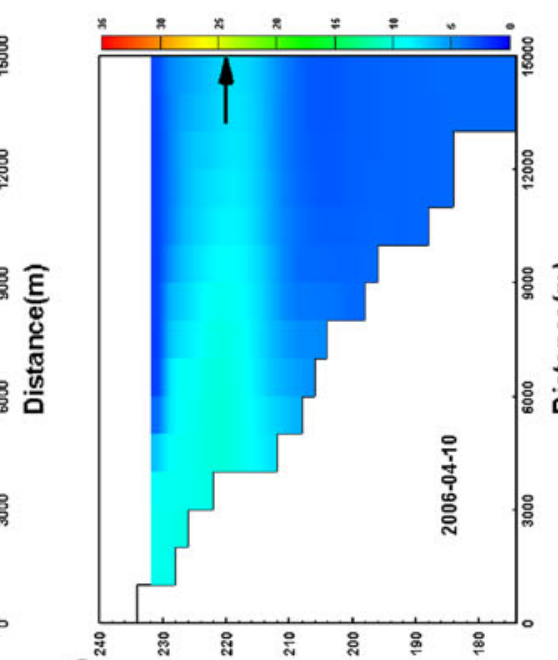

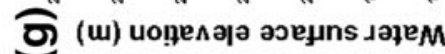

年 
was conducted with a certain amount of mass, $m_{0}$, of a conservative tracer injected at time $t_{0}$ and at a certain location. The time varying tracer mass, $m(t)$, remaining in the water body is then measured. The quantity $m(t)$ is found from the spatial integration of the measured concentration field within the water body, and its decline over time reflects the net rate at which the tracer leaves the water body. The rate of mass loss as a function of time $r(t)$ provides the residence time distribution, $\varphi(t)$,

$r(t)=\varphi(t)=-\frac{1}{m_{0}} \frac{\mathrm{d} m}{\mathrm{~d} t}$

Eq. (1) represents the residence time distribution of unit $[T]^{-1}$. The mean residence time, based on the first moment of $r(t)$, can be calculated as

$T_{r}=\int_{0}^{\infty} r(t) t \mathrm{~d} t=-\frac{1}{m_{0}} \int_{0}^{\infty} t\left[\frac{\mathrm{d} m}{\mathrm{~d} t}\right] \mathrm{d} t$

where $t$ is time and $T_{r}$ is the mean residence time.

One issue remaining in the application of Eq. (2) is the upper limit of the integration. Theoretically, the integration should be processed to the time when the residual mass reaches zero; in most circumstances, this may take an infinitely long time. In this study, $1 \%$ of the residual mass is designed to be the upper limit of the integration in Eq. (2).

A real case in 2006 was applied to calculate the mean residence time in the Shihmen Reservoir. The reservoir had a tracer concentration of 100 , and the model was run with real freshwater discharges from the upstream boundary in 2006. Figure 7 presents the snapshot plots of the simulated tracer concentrations on different days, showing that the residence time is approximately 154 days. Compared with the Sau Reservoir in northeastern Spain, the residence time in Shihmen Reservoir is longer (Rueda et al. 2006). However, the residence time is strongly correlated to the freshwater discharge from upstream boundaries.

\section{Conclusion}

A two-dimensional hydrothermal and water quality model, CE-QUAL-W2 was configured for the Shihmen Reservoir in northern Taiwan. The model was validated with measured data of water surface elevation, water temperature, and concentration of suspended solids in 2006. A close match was reproduced between the simulated and measured water surface elevation. The hydrothermal model reproduced the temporal and spatial distributions of the temperature in the water column during the simulations periods. The model results also closely mimic the measured
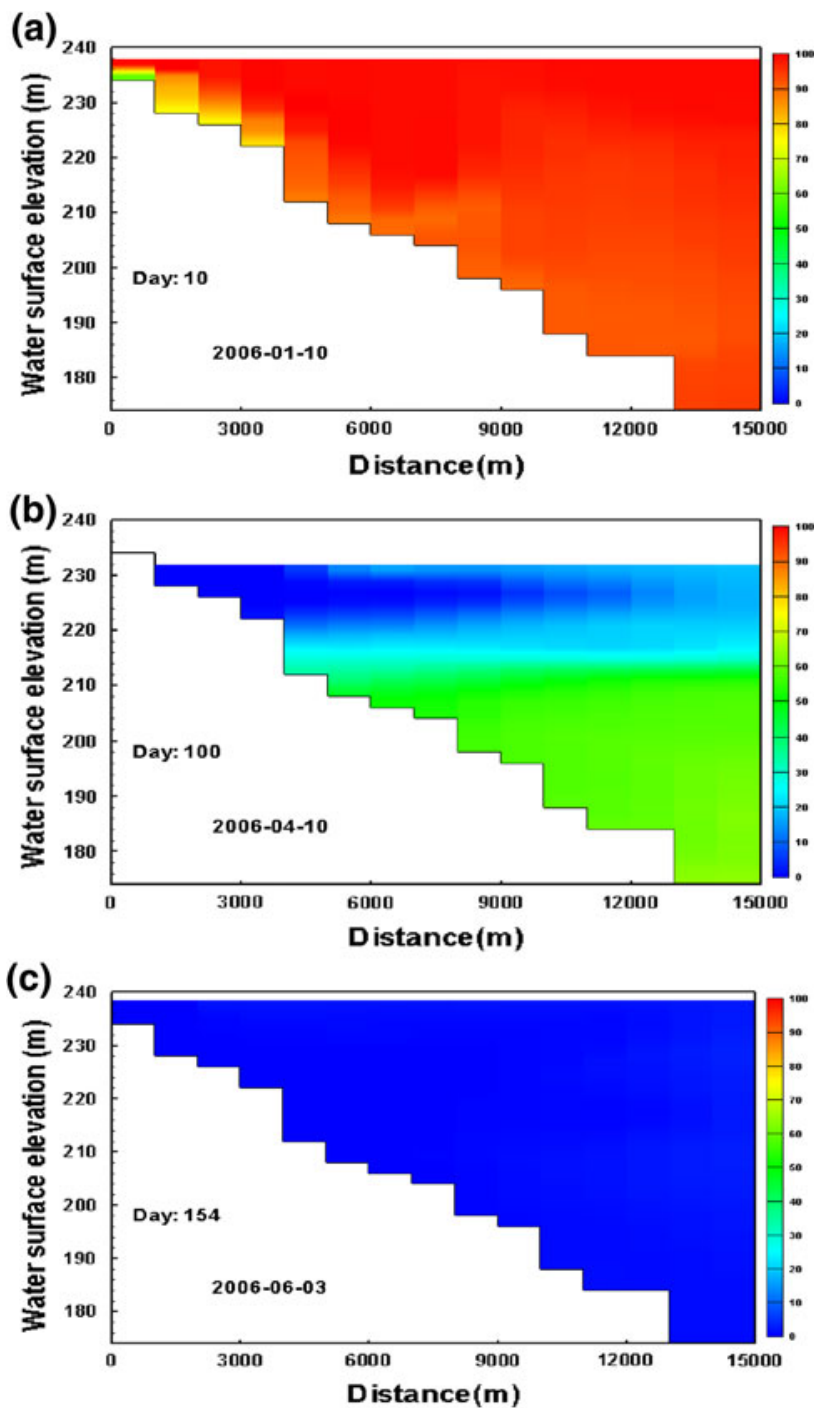

Fig. 7 Modeling tracer distribution for estimating residence time ( $\sim 154$ days $)$ in 2006

data of the suspended solids concentration. The validated model was then applied to investigate the effects of water withdrawal schemes at different depths and to estimate the residence time in the reservoir.

When water is withdrawn from a great depth, the relatively warm water from the upper layers can replace that in the deep layers, thereby, facilitating heat transfer from the surface to the deeper layers. The magnitude of such thermal structure changes depends on the water withdrawal depth, the withdrawal rate, the hydrodynamic and meteorological conditions, and the strength of the thermal stratification, which suggests that withdrawal from certain depths can facilitate water mixing and weaken thermal stratification in the water column. The plunging and separation depths and the vertical extent of the plume are 
greatly affected by the changing of withdrawal depths at the dam site of the Shihmen Reservoir. Bottom-water withdrawal results in a lower SS concentration compared with withdrawal from $20 \mathrm{~m}$ and $40 \mathrm{~m}$. A numerical experiment was conducted with a tracer concentration to estimate the residence time. The simulated results revealed that the residence time is approximately 154 days in the Shihmen Reservoir.

Acknowledgments The research was conducted as part of a grant supported by the National Science Council, Taiwan, Grant No. 96-2628-E-239-012-MY3. This financial support is greatly appreciated. The authors would like to thank the Northern Region Water Resources Bureau for providing the measured data used in the model validation.

\section{References}

Afshar A, Saadatpour M (2009) Reservoir eutrophication modeling, sensitivity analysis, and assessment: application to Karkheh Reservoir, Iran. Environ Eng Sci 26(7):1227-1238

Ambrosetti W, Barbanti L, Sala N (2003) Residence time and physical processes in lakes. J Limnol 62(1):1-15

Bartholow J, Hanna RB, Saito L, Lieberman D, Horn M (2001) Simulated limnological effects of the Shasta Lake temperature control device. Environ Manage 27(4):609-626

Chung SW, Gu RR (2009) Prediction of the fate and transport processes of Atrazine in a reservoir. Environ Manage 44(1):46-61

Cole TM, Buchak E (1995) CE-QUAL-W2: a two-dimensional laterally averaged, hydrodynamics and water quality model, version 2.0. US Army Engineers Waterway Experiment Station, Tec. Report EL-95-May 1995, Vicksburg, MS

Cole TM, Wells SA (2000) Hydrodynamic modeling with application to CE-QUAL-W2. Workshop Notes, Portland State University, Portland, OR
De Cesare G, Schleiss A, Hermann F (2001) Impact of turbidity currents on reservoir sedimentation. J Hydraul Eng ASCE 127(1):6-16

Etemad-Shahidi A, Afshar A, Alikia H, Moshfeghi H (2009) Total dissolved solid modeling; Karkheh Reservoir case example. Int J Environ Res 3(4):671-680

Ford DE (1990) Reservoir transport processes. In: Thorton KW, Kimmel BL, Payne FE (eds) Reservoir limnology, ecological perspective. Wiley, New York, pp 15-41

Gelda RK, Effler SW (2007) Modeling turbidity in a water supply reservoir: advancements and issues. J Environ Eng ASCE 133(2):139-148

Kim Y, Kim B (2006) Application of a 2-dimensional water quality model (CE-QUAL-W2) to the turbidity interflow in a deep reservoir (Lake Soyang, Korea). Lake Res Manage 22(3):213222

Kirk KL (1991) Inorganic particles alter competition in grazing plankton: the role of selective feeding. Ecology 72(3):915-923

Kuo JT, Liu WC, Lin RT, Lung WS, Yang MD, Yang CP, Chu SC (2003) Water quality modeling for the Feitsui Reservoir in northern Taiwan. J Am Water Resour Assoc 39(3):671-687

Rueda F, Moreno-Ostos E, Armengol J (2006) The residence time of river water in reservoirs. Ecol Model 191(2):260-274

Soeken-Gittinger LA, Stoeckel JA, Havel JE (2009) Differing effects of suspended sediments on the performance of native and exotic Daphnia. Freshw Biol 54(3):495-504

Sullivan AB, Jager HI, Mayers R (2003) Modeling white sturgeon movement in a reservoir: the effect of water quality and sturgeon density. Ecol Model 167(1-2):97-114

Thornton KW, Kimmel BL, Payne FE (1990) Reservoir limnology: ecological perspectives. Wiley-Interscience, New York

Wetzel RG (2001) Limnology-lake and river ecosystems, 3rd edn. Academic Press, London

Zhang H, Culver DA, Boegman L (2008) A two-dimensional ecological model of Lake Erie: application to estimate dreissenid impacts on large lake plankton populations. Ecol Model 214(2-4):219-241 